\title{
The Generalized Case Teaching Method and the Teaching of Petroleum Engineering HSE Risk Management
}

\author{
Zhengjun Long \\ Petroleum and Natural Gas Engineering College \\ Chongqing University of Science \& Technology \\ Chongqing , China \\ e-mail: longzj7252@sina.com
}

\author{
Jumei Liu \\ Petroleum and Natural Gas Engineering College \\ Chongqing University of Science \& Technology \\ Chongqing, China \\ e-mail: cqliujumei@yahoo.com.cn
}

\begin{abstract}
In this paper, the concept of generalized case teaching method is proposed, and its characteristics are stated. In order to adapt to different contents, aims and process of teaching, teaching cases are classified in five sorts, according to the functions of case, namely discussion and analysis case, experience-sharing case, application case, display case and workshop scenarios case. The different cases have different functions in classroom teaching. A specific attempt of case teaching method on the teaching of Petroleum Engineering HSE Risk Management is also introduced in this paper.
\end{abstract}

Keywords case teaching method; characteristic ; case function ; application

\section{INTRODUCTION}

Socrates, the famous philosopher of ancient Greek, is a pioneer who proposed the idea of case teaching method which originally means the way of discussing problems. Modern case teaching method was grown up in the Business Administration College of Havard University and it was mainly applied in teaching for industrial and commercial administration, marketing management. Case method is also called specific case method. Until 1984 when WACRA (World Association for Case Method Research and Application) was established, case method was widely adopted on laws, enterprise Management, medicine, clinical psychology, public, social work, politics, and news etc [1][2].

Generally speaking, the case method is a case discussion in class, the teacher guide students to discuss and analyze a specific case according to the requirement of target and content of teaching. This method can make the students think actively and initiatively to search after solution to the problems. It is different with traditional teaching method which emphasizes on teaching; it covers the teaching and learning, which stresses on teacher and students' communication, and stimulates students' interest and enthusiasm. The application of case method is helpful to enhance teaching quality and improve effect, and foster the students' ability of understanding, analyzing and resolving problems.

The Petroleum Engineering HSE ( H-Health, S-Safety, E-Environment ) Risk Management is a course for undergraduate students of petroleum engineering. The course is intensive knowledge and comprehensiveness, which includes HSE laws, regulations, management standard, theory of accident control and precaution, the management and technical knowledge of health safety and environmental protection on petroleum engineering and so on. It also relates to hazard risk identify and assessment, control methods and the technique of petroleum engineering drilling and production[3]. Based on the uniqueness of petroleum engineering HSE risk management, generalized case teaching method is inducted in the teaching.

The generalized case teaching method is an improved teaching method, witch applies different relevant cases in the whole teaching process and uses different teaching methods such as role-playing, interpretation, analysis, question, discussion, observation and investigation in working field. As a result, it can raise students' interests so as to encourage them to participate in class.

On one hand, the generalized case teaching method inherits the advantages of traditional teaching method; on the other hand, it has unique features. The application of generalized case teaching method in the course of petroleum engineering HSE risk management has shown excellent teaching results.

\section{THE CHARACTERISTICS OF GENERALIZED CASE TEACHING METHOD}

\section{A. Outstanding Practicalness}

The most prominent feature of case teaching method is that the lecture started from practice case. In the course of the HSE Risk Management of Petroleum Engineering, each lesson begins with a real-life case; by raising questions based on practices, relevant rules are identified through analyzing, so the theory can be refined and applied to guide future practices. There is essential difference between the generalized case teaching and giving examples in lecture, as latter serves to justify the theories taught by the teacher and pass on theoretical knowledge, while former one has richer connotation in its examples, which involves a wider range of knowledge and a more complicated process for analysis and resolution. Therefore, students should be equipped with not only theoretical knowledge, but also some know-how, experience and common sense. Through this process, the conversion from practice to theory and from theory to practice is achieved. 


\section{B. Strong Pertinence}

According to the teaching requirements of course section or each lesson, pointed cases related to teaching topic and aims is chosen to introduce the topic and to invite relevant questions and discussions, so the role of cases in teaching is realized and discussed through the introduction of problem and point to reflect the case role in teaching.

\section{Clear Purpose.}

Through reading, thinking, analyzing and discussing one or several unique and representative typical accident case, students are trained to form their own way of logical thinking and reasoning so that their ability of analyzing and solving questions are improved, their horizon of knowledge are broadened, and their individual qualities are enhanced. There are various teaching objectives in classroom teaching; to fulfil these objectives, different kinds of cases and teaching methods are adopted in teaching design.

\section{Objectivity and Authenticity}

The cases describe real-life stories, which decide the authenticity of case teaching. The students can develop their own understanding and conclusions based on their own understanding and the knowledge they learned from cases.

\section{E. Comprehensiveness}

There are diversified cases, involving a wide range of knowledge and rich connotation and inviting question in many aspects. The cause of the accident is complex; it often involves the factors of the human, machine, environment and management. The analysis of cause for accidents and the proposed precaution measures not only relate to the fundamental theories and technical expertise of the subject, but also personal experience and comprehensive quality of students.

\section{F. Enlightening and Participation}

Students can be enlightened by learning ,discussing and analyzing real-life cases, while their initiatives can be enticed as these cases may contain references to them, indicate a close relationship to them, or because the cases are authentic and vivid. Students can be turned into active learners and explorers or knowledge rather than a passive end of teaching, and they can really master their own learning and consider it as a pleasure [4].

\section{G. Multiformity of Teaching Method}

There are no absolutely correct answers to cases when adopting generalized case teaching method, as the method focuses on cultivating students' ability of independent thinking and inspiring them to establish a set of thinking patterns for analyzing and solving problems. The teaching methods adopted are flexible, as they can be in forms of questioning based on cases, group discussions or individual analysis report. The teaching methods include that teacher commentates case and brings up questions; students discuss in group and independently complete analysis report and so on.

\section{H. Multiple Functions of Cases}

Various case types are introduced in classroom teaching based on different teaching objectives and teaching contents, for which they play different roles. Besides, various forms of the carriers, contents and learning requirements of cases lead to diversified teaching modes. The functions of cases change when the learning requirements of cases change, which indicates the flexibility of the roles cases play. The multiple functions of cases as well as the diversity of teaching method fully demonstrate the unique generalized characteristics of the case teaching method.

\section{THE STYLES AND FUNCTIONS OF CASES}

Different cases and case types are adopted according to the characteristic of the curriculum content, different teaching objectives and different teaching links of HSE Risk Management of Petroleum Engineering. Distinct from traditional case teaching method, cases are classified based on their functions as discussion and analysis, experiencesharing, application, display, and workshop scenarios case.

The cases have reference with occupation health, safety and environment, including typical accident, experience, theory and technology cases, stories, allusions etc. Cases are displayed by different media including videos, cartoons, photos, PPT, text documents. Various case types play different roles in classroom teaching.

\section{A. Discussion and Analysis Case}

As implying by the name, these cases are used for classroom discussion and analysis. For example, in a case of a typical environmental pollution accident, students learn about the accident through reading documents or watching videos and then discuss and analyze the direct and indirect causes of the accident, the nature of the accident, and the persons responsible for the accident. Therefore, the lessons from the accident are drawn, awareness and measures of accident prevention are developed, and students' comprehensive abilities of recognizing, analyzing and solving problems are cultivated.

\section{B. Experience Sharing Case}

This case type indicates a summary, collection and classification of lessons drawn from HSE accidents, as well as safety working approach and cases regarding typical safety experience (from accidents and allusions). Through sharing and exchanging ideas of accidents, students are enlightened so that they can infer other things from one fact and get twice the result with half the effort.

\section{Application Case}

The cases that apply classical theory, technology, method and tool in practices are called application case. The case studies help students deepen their understanding about the theoretical knowledge and facilitate the integration of 
knowledge and application. It also contributes to comprehending and mastering the technologies, methods and tools that the cases involved. Meanwhile, it also benefits expansion of students' knowledge. This type of cases mainly serves as practices for students after classes.

\section{Display Case}

This type of case described the origin, process, reason, result and conclusion of a true incident or accident in all directions, including detailed description of theme connotation, principles, key problems, solutions and analysis process. It is called display case because it fully displays elements of the case and analysis process. It is mainly used for students' self-study, as students can learn the skills and methods of analyzing and solving problems from it. In addition, this case may also be used in classroom teaching as it fully analyzes, displays and explains the case, it is also known as explanation case.

\section{E. Workshop Scenarios Case}

This type of case describes a real-life production scene, from a set of equipments and facilities, a petroleum station, a worksite, to a pipeline, a work field or the big picture of a production enterprise, while the equipments, facilities, settings, production techniques and surroundings in the scene being described in details.

Shown in videos, cartoons, pictures or texts, it can help students identify HSE risks and evaluate comprehensive control exercises. A comprehensive workshop scenario case can also be applied in integrated practices such as detecting and analyzing potential safety hazard and management defects as well as in accident prevention and improvement plan designs. These practices can be done on-site when applicable.

\section{THE APPLICATION OF GENERALIZED CASE METHOD IN THE CLASSROOM}

\section{A. Preparation of Case}

Preparation and compiling of the case is the prerequisite and basis for implementation of case teaching and also the key of the application of generalized case method. In the light of teaching content of HSE Risk Management of Petroleum Engineering, more than 100 various types of case are collected and complied. Case forms and content are closely linked with course content; in addition to videos, cartoons and text materials, a lot of pictures involved the field equipment facilities system [4].

\section{B. Case Teaching Design and Case Application}

In the course of classroom teaching about Petroleum Engineering HSE Risk Management, different teaching forms and different case are adopted according to teaching content and teaching objectives[5].

The typical classroom teaching idea means including 2 3 cases in the whole teaching process according to the teaching contents, with each class beginning with a sharing of experience case to introduce the topics. This teaching process is also called safety experience sharing. To attract students' attention and interests, the cases are often shown in multimedia such as videos, flashes. The contents of case usually involve both positive and negative aspects of the case. The teacher put forward question before or after showing the case to guide and inspire students' own thinking. The students can share their experience and knowledge with the form of answering a question by giving solutions to problems after case studying. While sharing experience, an interesting and vivid case enables the teacher and students to share the fun of learning.

The display cases along with the analysis and discussion cases are alternatively applied in classroom teaching as the teaching content requires. Through independent learning of display cases in addition to instructions from the teacher, students can integrate the case with the theories, principles and methods learned in class so that they not only understand and master the knowledge better, but also build their thinking pattern and the abilities of identifying, analyzing and solving problems.

There are two ways to applying discussion and analysis cases. One is for small group discussions that are desirable to be 10 to 15 minutes. The other is for discussions among all the students, which is desirable in a seminar. The classroom teaching would be more dynamic with all the students involving in the case discussion, analysis and exchanging ideas. Every student should participate in case discussions, analysis and exchange, to make classroom teaching more active and lively. One or two seminars can be arranged in the teaching process. Beginning with group discussions for consensus in each group, representative are elected in each group to exchange ideas with others and get comments from students and the teacher.

After the instructions of the relevant theories, principles, techniques, the lecture could assign application cases to students and require them to finish exercises after studying the cases. By this way, students could deepen their understanding of relevant knowledge and master the techniques for application. This teaching of application case can be in classroom or on worksite. For example, risk analysis for drilling, oil product locating and other relevant work safety analysis can be conducted in worksite. Through actual operation and observation, students can be aware of the risk factors in the operation process, and thus the identification, evaluation, analysis and control of risks are brought to practices closely.

\section{Instances of case applications}

Two cases below are adopted in classroom teaching of this course to demonstrate their roles.

\section{Case 1: The blind man with a lamp}

Once upon a time, a blind man carrying a lantern was walking down the street at night. Someone asked: "you can not see anything, why do you take the lamp with you?" The 
blind man answered: "When I do so, others would be able to see me and not knock me down."

\section{Question:}

In the view of safe production, what can the story tell us?

This is an experience-sharing case from a Chinese ancient literary quotation. Through the questions based on case studies, students are inspired and enabled to understand the philosophy of the literary quotation just like the blind walking with a lamp at night to avoid being hurt by others, the philosophy of safety measures i.e. "it makes sense to take measures to avoid being hurt" are demonstrated, and the principle of "Do Not Be Harmed" from the "Three Do Not Harm Principles" in safe production is demonstrated because are clearly stated. What the blind did is worth following, since only mutual supervision and reminding during production can secure a safe production. Discussions about the case should be introduced from the beginning of the lecture, followed by the topic of risk control measures.

\section{Case 2: Unsafe behavior and unsafe state of the}

\section{objects caused the accident}

One day, blowout happened while drilling high-pressure gas reservoir, drilling mud were pumped to the mixing tank for weighing by a small cycles pipeline, while a mud technician of the drilling team who had just graduated from college went across the mud line to the tank to pick up the mud samples, he was knocked to the ground and died instantly by raising pipeline because the pipeline was not fixed firmly and pipeline pumping pressure release[6].

\section{Exercises:}

Try analyze and discuss the cause of the accident with the idea of "the trajectories cross theory of accident causation", and propose accident prevention measures.

Shown as a text document, this is an Application Case based on a real personal injury accident. After studying the case, students are required to present their understanding of the "trajectories cross theory of accident causation" and to describe the risk factors from human behaviors (Unsafe behavior across the high pressure loop pipeline), factors regarding movement tracks and objects( E.g. Pressure circulation pipeline is not fixed firmly in a state of insecurity) and how intersection of movement tracks lead to the accident, so that they could put forward accident prevention measures.

On the one hand, discussions about the case combine the theories with practice and help deepen understanding of the theories; on the other hand, a vivid accident case would narrow the gap between theory and practice and also help raise students' interests of learning without a doubt.

After explaining the "trajectories cross theory of accident causation", the lecture could introduce the case and have students discuss about it in groups. The students may present their own ideas about the theory so that the lecturer is enabled to find out how well the students understand about his or her instructions.

Besides, this Discussion and Analysis Case can be changed into an Application Case if the exercise is changed to be "Try analyze and discuss the cause of the accident with the idea of' the trajectories cross theory of accident causation', propose accident prevention measures, and present ideas in an 800-1000words essay.” This exercise can be done as an assignment for students.

\section{CONCLUSIONS}

Typical case teaching method is widely used in the professional fields of both arts and science, from business administration, corporation governance, legal services, public administration, social work, to politics, journalism.

According to the curricular system characteristics of engineering, there is positive meaning in exploring the application of the generalized case teaching method as it broadens the range of application of the method.

It is proved by practices that applying the generalized case teaching method in the course of Petroleum Engineering HSE Risk Management gives desirable results, representing by the dynamics in the class, the increased learning interests, the broaden mind and the noticeably higher active participation.

[1] Jiemin Zhang, Case teaching method-theory and Practice.(Beijing: Jiuzhou press), 2006, pp13-21

[2] Lorry..Harvard Business School MBA Case Book.(Beijing: Economic Daily Press) 2001, pp125

[3] Wenhai Li, Zhengjun Long, Petroleum Engineering HSE Risk Management. (Beijing: Petroleum Industry Press) 2008, pp23-42

[4] Jumei Liu, Zhengjun Long, “The primary pxploration of case-based teaching in HSE risk mangement teaching, IEEE Press. J. Singapore: pp350-353,2011.

[5] Zhengjun Long, Wenhua $\mathrm{Li}$ et al, “Application of caes teaching method on the teaching of petrolum engineering HSE risk management" J.Journal of Chongqing University of Science and Technology. China, vol. 165, pp191-193, Feb. 2012.

[6] Qingli Yang etc, Cases Collection of Blowout Accidents on China National Petroluem Corporation. (Beijing: Petroleum Industry Press) 2006, pp107-111. 